\title{
A OBSTETRIZ NO CAMPO DO ENSINO
}

\author{
Dilce Rizzo Jorge *
}

$\mathrm{RBEn} / 10$

JORGE, D.R. - A Obstetriz no campo do ensino. Rev. Bras. Enf.; 28 : 71-76, 1975.

\section{I - INTRODUÇÃO}

O objetivo deste trabalho, é ressaltar a importância do preparo da obstetriz docente e sua responsabilidade na formação de novas profissionais que vão atuar nas diversas áreas de atividade relacionadas com a assistência materno-infantil.

Essa assistência, definida pela Comissão de Peritos de Maternidade da Organização Mundial da Saúde, nos mostra quão vasto é o programa a ser cumprido pela obstetriz e consequentemente, quanto a docente deve estar preparada para transmitir ensinamentos. Assim se expressa a comissão:

"A finalidade do cuidado à maternidade é assegurar que, toda a gestante e toda a mãe que amamenta, mantenha boa saúde, aprenda a cuidar do filho, tenham parto normal e procriem crianças sadias. Esse cuidado no sentido estrito consiste em assistência à getante, segurança no parto, cuidado da puerpera, exame pós puerperal, cuidado aQ recém-nascido e estímulo à manutenção da lactação. No sentido lato ela começa bem cedo, com medidas que visam a pro- moção da saúde e do bem estar dos jovens, que são pais em potencial, preparando-os para a vida familiar e destacando o papel da família na comunidade. Deveria também incluir educação sexual e a compreensão de problemas associados à esterelização e ao planejamento familiar".

\section{II - CONSIDERAÇÕES SOBRE A FORMAÇÃO DO PROFESSOR}

No decorrer da história sempre houve preocupação pelo preparo de professores e esses eram considerados pessoas sábias. Somente no decorrer da Idade de Ouro na Grécia, o magistério tornou-se uma profissão. No século I depois de Cristo já existia, bem definida a ciência da pedagogia (6) e era evidente a importância que se atribuía ao mestre. Nos fins do século XVI, as várias ordens católicas aceitaram a responsabilidade da educação dos jovens e estabeleceram programas para a formação do professor. Os programas de formação de professores também receberam impulso na

* Professora da Escola de Enfermagem da USP. 
JORGE, D.R. - A Obstetriz no campo do ensino. Rev. Bras. Enf.; 28 : 71-76, 1975.

Alemanha durante a época de Frederico, o Grande (1712-1786). Reconhecendo a necessidade de certas normas para avaliar a função dos professores num sistema de educação e de uma preparação comum, foram estabelecidos institutos para futuros mestres e mais tarde, para os que já exerciam a profissão.

No decurso dos anos tem variado o tipo de preparação do pessoal docente, mas sempre houve reconhecimento de que o magistério é uma profissão que possui métodos próprios e um acervo próprio de conhecimentos, e que, representa uma forma particular de trabalho.

O trabalho do professor consiste em aperfeiçoar indivíduos e, por esse motivo, além de preparado para o que vai ensinar, deve conhecer o material com que vai lidar. Comparando o professor ao artífice, este aprende cedo sobre a natureza do material que usa, para entregar ao consumidor um objeto utilizável e de qualidade. Mas o professor muitas vezes exerce o seu trabalho sem o conhecimento completo do material com que lida. A diferença entre o artífice e o mestre é que, este lida com material vivo, que é o aluno, e por isso deve harmonizar o objetivo da educação com o crescimento do indivíduo e com o sentido de consciência e de responsabilidade por parte do estudante: para entregar à sociedade um profissional de qualidade.

A especialização tem se verificado em todos os campos de atividade, mas, se o professor for somente especialista e souber pouco do mundo e da sociedade, sua contribuição será mecânica e transmitirá seus conhecimentos fora da realidade, sem uma visão de conjunto. Ter conhecimentos de uma determinada disciplina não faz o professor; além disso, deve ter qualidades humanas. De acordo com Luzuriaga, (11) "o docente não precisa ser um santo, um gênio ou herói, basta que seja um bom educador com qualidades sintetizadas na seguinte tábua de valores:

- vocação, interesse, atração pela educação;

- amor, afeto, simpatia pelos alunos, sensibilidade e inteligência para compreendê-los;

- condições físicas de saúde, resistência e agilidade;

- atrativo pessoal, graça, tato, humor;

- carater, personalidade, autoridade;

- cultura geral, interesse pela ciência;

- arte, capacidade, destreza, técnica docente;

- moralidade pessoal e profissional;

- senso social, espírito humano".

Diz ainda que, não sendo possível reunir todas essas qualidades, deve-se aspirar possuí-las no maior número possível. (4)

A combinação saber, busca da verdade, bom critério e integridade são qualidades típicas dos mestres em qualquer especialidade.

Com relação à formação do professor existem duas afirmações opostas: a) $O$ professor deve ter dons naturais nasce feito; b) o professor deve aprender o seu ofício.

Essas cuas afirmações se completam, porque sem aprender o seu ofício jamais utilizará os seus dons naturais. E, também nunca utilizará bem os seus dons naturais se não aprender o seu ofício.

O professor também não pode ser um simples "tarefeiro" que realiza a sua função meramente para ganhar a vida, embora deva ser devidamente remunerado. Não pode ser um simples funcionário que burocraticamente cumpre sua missão sem interesse nem entusisamo. Também não pode ser um simples agente de ensino que limita o seu papel a ensinar umas tantas noções ou regras. Deve possuir preparo especial no mais elevado grau possível. 
Luiz Vives (7), caracterizou o professor, não somente como pessoa que sabe muito para ensinar, como também deve ser pessoa de costumes puros. Esta caracterização especialmente se aplica à obstetriz docente, porque a sua conduta tanto particular como profissional influirá na formação de jovens que irão exercer uma profissão que dá amplas oportunidades de desvios.

Outro aspecto que deve ser salientado, é a tendência atual de destacar o prestígio científico. Há o perigo das obstetrizes se tornarem ótimas técnicas e cientistas e menos humanas. A formação que a docente deve dar às futuras obstetrizes não deve ser somente técnica e cientista, mas imbuí-las de espírito de humanidade, o que é altamente necessário para a qualidade de assistência que a profissional irá oferecer à comunidade.

Enfim, o professor, além de grandes conhecimentos, deve possuir uma qualidade superior que suscite o respeito de todos baseada numa atitude de integridade pessoal, qualidade essa importante para os estudantes que recorrem à instrução e orientação.

\section{III - EVOLUÇÃO DO PREPARO DA OBSTETRIZ PARA A DOCENCIA NA UNIVERSIDADE DE SATO PAULO}

Na antiga Escola de Obstetrícia, desde o seu início em 1912 até 1955, as obstetrizes prestaram contribuicão no ensino prático das alunas. Trabalhavam na clínica e ao mesmo tempo ensinavam. Não havia exigência de preparo especial para essa função, bastava o diploma de conclusão do curso de obstetricia.

De 1955 a 1963, a Escola passou a admitir obstetrizes para ministrar o ensino prático de assistência obstétrica, teoria e prática das disciplinas de enfermagem. Nesse período também não era exigida formação especial, bastava o diploma e qualidades demonstradas durante o curso.

Em 1964, a seleção das docentes passou a ser mais rigorosa quanto ao nível de escolaridade e exigência de pós graduado em pedagogia e didática, além de outros.

Em 1970 a Reforma Universitária trouxe grandes transformações na estrutura das universidades brasileiras. "Fixou os princípios gerais de uma filosofia da docência universitária e reformulou o estatuto do magistério, atendendo às questões fundamentais no que se refere à atividade de docência e investigação, reconhecendo a indissolubilidade da docência e pesquisa. O princípio implícito na idéia de unificação de carreira universitária, é que, todo o professor deve investigar e de algum modo criar e também ensinar". (1)

E assim, de acordo com o Estatuto da Universidade de São Paulo, a carreira docente obedece ao princípio de integração de atividades de ensino, pesquisa e extensão de serviços à comunicadade. Compreende os seguintes cargos e funções:

$$
\begin{aligned}
& \text { I - Professor assistente } \\
& \text { II - Professor assistente doutor } \\
& \text { III - Professor livre docente } \\
& \text { IV - Professor adjunto } \\
& \text { V - Professor titular }
\end{aligned}
$$

Hoje a obstetriz, como qualquer outro profissional, para iniciação das atividades docentes, na Universidade de São Paulo, é admitida como Auxiliar de Ensino, mediante contrato de 3 anos, estando vinculado ao programa de ensino e pesquisa. As oportunidades para fazer a carreira docente dependem de cursos de pós-graduação que levam ao mestrado e doutoramento.

A Reforma Universitária previa a unidade de funções de ensino e pesquisa, vedada a duplicação de meios para fins idênticos ou equivalentes. (2) 
A Universidade de São Paulo, reconhecendo a similaridade dos Cursos de Enfermagem e de Obstetrícia em 1971 através da Portaria do Reitor de n. ${ }^{0} 1398$ de 18-2-1971, integrou a Escola de Obstetrícia anexa ao Departamento de Obstetrícia e Ginecologia da Faculdade de Medicina à Escola de Enfermagem de São Paulo. O ensino teórico de Obstetrícia Normal e Patológica, ficou sob a responsabilidade do citado Departamento. A enfermagem obstétrica ginecológica, neo-natal e assistência a gestante, parturiente e puerpera, sob a responsabilidade das docentes obstetrizes e enfermeiras obstétricas da Escola de Enfermagem. As obstetrizes não só ensinam na habilitação em obstetrícia, como no tronco profissional comum e na habilitação em saúde pública.

O capítulo seguinte dará esclarecimentos sobre o tronco profissional comum e as habilitações.

\section{IV - O NOVO CURRÍCULO DOS CURSOS DE ENFERMAGEM E OBSTETRICIA}

O curso de enfermagem regia-se pelo Parecer 271/62. O Parecer 303/63 do Conselho Federal de Educação, que modificou o Parecer 271/62, estabeleceu os currículos mínimos para os Cursos de Enfermagem e de Obstetrícia dando a possibilidade dos dois cursos se complementarem, assim como, de serem ministrados num tronco comum de 2 anos e o terceiro diversificado.

Em virtude da Reforma Universitária, os currículos dos cursos superiores foram revisados e o Parecer $163 / 72$ do Conselho Federal de Educação, verificou que havia dois currículos similares que se completavam e reformulou os currículos dos cursos de Enfermagem e de Obstetrícia. Este novo currículo (anexo II) poderá contribuir para melhor formação das futuras profissionais, dando bases para assistir mais eficientemente a comunidade, como para a continuação do preparo da futura docente.

O parecer estabelece 3 partes sucessivas do currículo:

\section{1) Parte pré-profissional}

Compreende as seguintes matérias:

- Biologia - incluindo noções fundamentais de Citologia, Genética, Embriologia e Evolução;

- Ciências Morfológicas - incluindo Anatomia e Histologia;

- Ciências Fisiológicas - incluindo Bioquímica, Fisiologia, Farmacologia e Nutrição;

- Patologia - compreendendo Processos Patológicos Gerais, Imunologia, Parasitologia e Microbiologia;

- Ciências de Comportamento - incluindo noções de Psicologia e Sociologia;

- Introdução à Saúde Pública - incluindo Estatística Vital, Epidemiologia, Saneamento e Saúde da Comunidade.

2) Tronco profissional comum

Abrange as seguintes matérias:

- Introdução à Enfermagem

- Enfermagem Médico-Cirúrgica

- Enfermagem Materno-Infantil

- Enfermagem Psiquiátrica

- Enfermagem em Doenças Transmissíveis

- Exercício da Enfermagem - incluindo Deontologia Médica e Legislação Profissional

- Didática. Aplicada à Enfermagem

- Administração Aplicada à Enfermagem.

3) Parte de habilitações

Com as matérias grupadas abaixo:

I - para a habilitação em Enfermagem Médica-Cirúrgica: 
JORGE, D.R. - A Obstetriz no campo do ensino. Rev. Bras. Enf.; 28 : 71-76, 1975.

Enfermagem Médico-Cirúrgica, incluindo Administração de Centro Cirúrgico, Enfermagem em Pronto Socorro, Unidade de Recuperação e de Cuidado Intensivo e Administração de Serviços de Enfermagem Hospitalar.

II - para a habilitação em Enfermagem Obstétrica ou Obstetrícia:

Obstetrícia - Enfermagem Obstétrica: Ginecologia e Neo-natal; Administração de Serviços de Enfermagem em Maternidades e Dispensários pré-natais.

III - para habilitação em Enfermagem de Saúde Pública:

Enfermagem de Saúde Pública e Administração de Serviços de Enfermagem em Unidades de Saúde.

Também ao graduado que receber em estudos regulares a formação pedagógica prescrita para os cursos de licenciatura, será concedido o Diploma de Licenciado em Enfermagem, com direito ao registro como professores de $1 .^{\circ}$ e $2 .^{\circ}$ graus das disciplinas relacionadas à Enfermagem Higiene e Programas de Saúde.

Quanto à duração dos Cursos de Enfermagem e Obstetrícia, o Parecer estabelece os seguintes modalidades mínimas de duração:

a) na habilitação geral de Enfermeiro -2.500 horas de atividades, integralizáveis no mínimo de (três) 3 e no máximo de (cinco) 5 anos letivos;

b) nas habilitações em Enfermagem Médico-Cirúrgica, Enfermagem Obstétrica e em Enfermagem de Saúde Pública - 3.000 (três mil) horas de atividades, no mínimo de (quatro) 4 e no máximo de (seis) 6 anos letivos;

c) na modalidade de Licenciatura além da parte de conteúdo prescrita para qualquer das modalidades anteriores - a formação pedagógica da Licenciatura exigida no Parecer $n .^{\circ} 672 / 69$.
O Curso de Enfermagem e Obstetrícia, nas habilitações Médico-Cirúrgica, Enfermagem Obstétrica ou Obstetrícia e Enfermagem de Saúde Pública terá duração mínima de 3.000 horas-aula, a serem integralizadas em no mínimo (quatro) 4 e no máximo (seis) 6 anos letivos.

O mínimo para o Curso de enfermagem é de 6 semestres e o máximo de 10 semestres.

O mínimo para o Curso de Obsterícia é de 8 semestres e o máximo de 12 semestres. O mesmo acontece com as outras habilitações.

A Escola de Enfermagem da Universidade de São Paulo, adotará o termo médio que é: 8 semestres para o curso de Enfermagem e 10 semestres para o Curso de Obstetrícia e das outras habilitações porque considera o mínimo insuficiente para o bom preparo da obstriz e da enfermeira.

Em linhas gerais, acredito ter levado ao conhecimento das interessadas, o que faz a obstetriz docente e o que lhe é exigido para o exercício de suas atividades no campo de ensino na Universidade de São Paulo.

\section{$\mathrm{V}$ - CONCLUSÃO}

No que diz respeito à formação da obstetriz para o magistério, não ha diferença dos outros profissionais docentes. As exigências de preparo e de conduta são as mesmas exigidas de todos os professores. A carreira docente está aberta a aquelas que se propuserem a aprender bastante para ensinar bem, e cujo desejo de ensinar seja uma vocação. Vocação e estudo completam o professor.

A obstetriz é a docente indispensável no ensino da obstetrícia, e seus conhecimentos e valores pessoais são importantíssimos para formar novas profissionais, porque a qualidade de assistência que estas irão oferecer à comunidade 
depende da formação que receberem de suas mestras obstetrizes que as acompanham passo a passo na prática da assistência obstétrica. Não esqueçam as professoras, que no mundo atual em rápida evolução, o ensino requer conhecimentos técnico e amplitude de critérios.

\section{VI - REFERENCIAS BIBLIOGRAFICAS}

1 - BRASIL - Ministério de Educação e Cultura. Reforma Universitária, Relatório do Grupo de Trabalho, Rio de Janeiro, MEC, 1968.

2 - BRASIL - Ministério de Educação e Cultura. Instituto Nacional de Estudos Pedagógicos, Ensino Superior, Coletânea de Legislação Básica, Rio de Janeiro, MEC.

3 - BRASIL - Ministério de Educação e Cultura, Parecer 163/72, Conselho Federal de Educação, Documento n. ${ }^{\circ} 135$.

4 - LUZZURIAGA, L. - Pedagogia, São Paulo, Ed. Nacional, 1968.

5 - NERICI, I.G. - Introdução à Didátí- ca Geral, Rio de Janeiro, Fundo de Cultura, 1965.

6 - ORGANIZAÇAO MUNDIAL DA SAÚDE - Enfermeira, Recopilacion de Trabajos, n. 3 Washington, OPS, abril, p. 154-173 (publ. científica n. $\left.{ }^{\circ} 176\right), 1969$.

7 - PENNA, L.D. - A Formação do Educador, São Paulo, Ed. Nacional, s.d.

8 - RIVERA, S.F. - Formação da Instrutura, Revista Brasileira de Enfergem, 10: 2, junho, 1957.

9 - SÃO PAULO, Universidade - Estatuto e Regimento da Universidade de São Paulo, São Paulo, Serv. Doc. USP, 1972. 